\title{
Education and Industry Partnerships: Development of Advanced Instrumentation Training Program at Columbia Basin College
}

\author{
R.A. Westberg ${ }^{1}$, C.C. Bunker ${ }^{2}$, E.P. Grimsrud ${ }^{2}$, and R.J. Lee ${ }^{2}$ \\ ${ }^{1}$ RJ Lee Group, Inc. - Center for Laboratory Science \\ ${ }^{2}$ RJ Lee Group, Inc. \\ ${ }^{3}$ Columbia Basin College
}

This involves the creation of a unique partnership between Columbia Basin College (CBC), a twoyear college in Pasco, WA and RJ Lee Group, Inc. This partnership has resulted in the founding of The Center for Laboratory Science (CLS) which has led the way towards developing curriculum for an Analytical Technology degree program at CBC. This program will address several educational, community, and industrial needs in the southeastern region of Washington State and serve as a model for future education-industry partnerships at the community college level. The development of the degree program includes providing access to advanced analytical instrumentation not typically found at the undergraduate level, including Transmission Electron Microscopy (TEM), Scanning Electron Microscopy (SEM), Inductively Coupled Plasma-Mass Spectrometry, and Gas Chromatography-Mass Spectrometry.

The initial phases of this partnership included the developing plans for a new, state of the art, laboratory facility which will house the Center for Laboratory Sciences. This facility will house CLS's analytical instrumentation, which serves both training and research efforts at CBC and local industry by providing commercial services for Environmental Chemistry, Forensic Science, Materials Characterization, and Contract Research.

The Analytical Technology degree program will provide students with applied learning opportunities through a comprehensive practicum program that will ensure success in the workforce or as they transfer to a four-year program. This includes utilization of CLS's advanced analytical instrumentation in a commercial laboratory setting. Further, students can apply for internships and student positions at CLS, which has found recent success in giving students the opportunity to provide materials characterization, analytical chemistry, and contract research support to local industry.

The Analytical Technology program also will contain components necessary to support the on-going needs of local industry, in particular, the Hanford Nuclear Waste Reservation and Pacific Northwest National Laboratory. The on-going efforts at this site require government employees to routinely seek out retraining programs that include hands-on experience with analytical chemistry and materials characterization instrumentation. The Hanford complex, combined with a plethora of supporting commercial entities that operate the site, bring roughly $\$ 2$ billion in annual revenue to Tri-Cities area businesses. The development of waste clean-up and sequestering technologies drives the need for trained scientists at the site and these efforts are currently being supported by instrumentation used at CLS by students, interns, CBC staff, and CLS employees. 


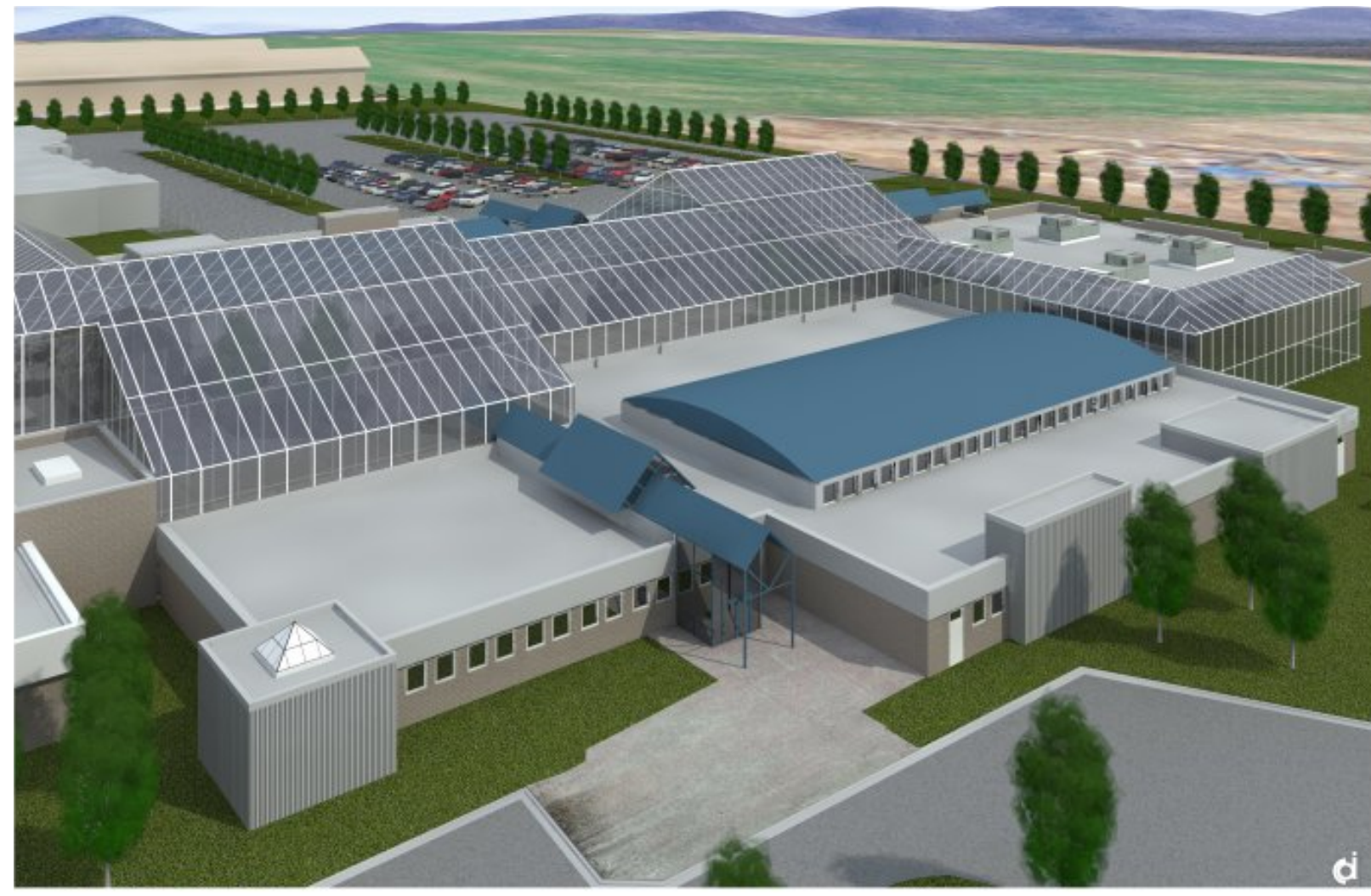

New laboratory facility under construction at Columbia Basin College - Pasco, WA

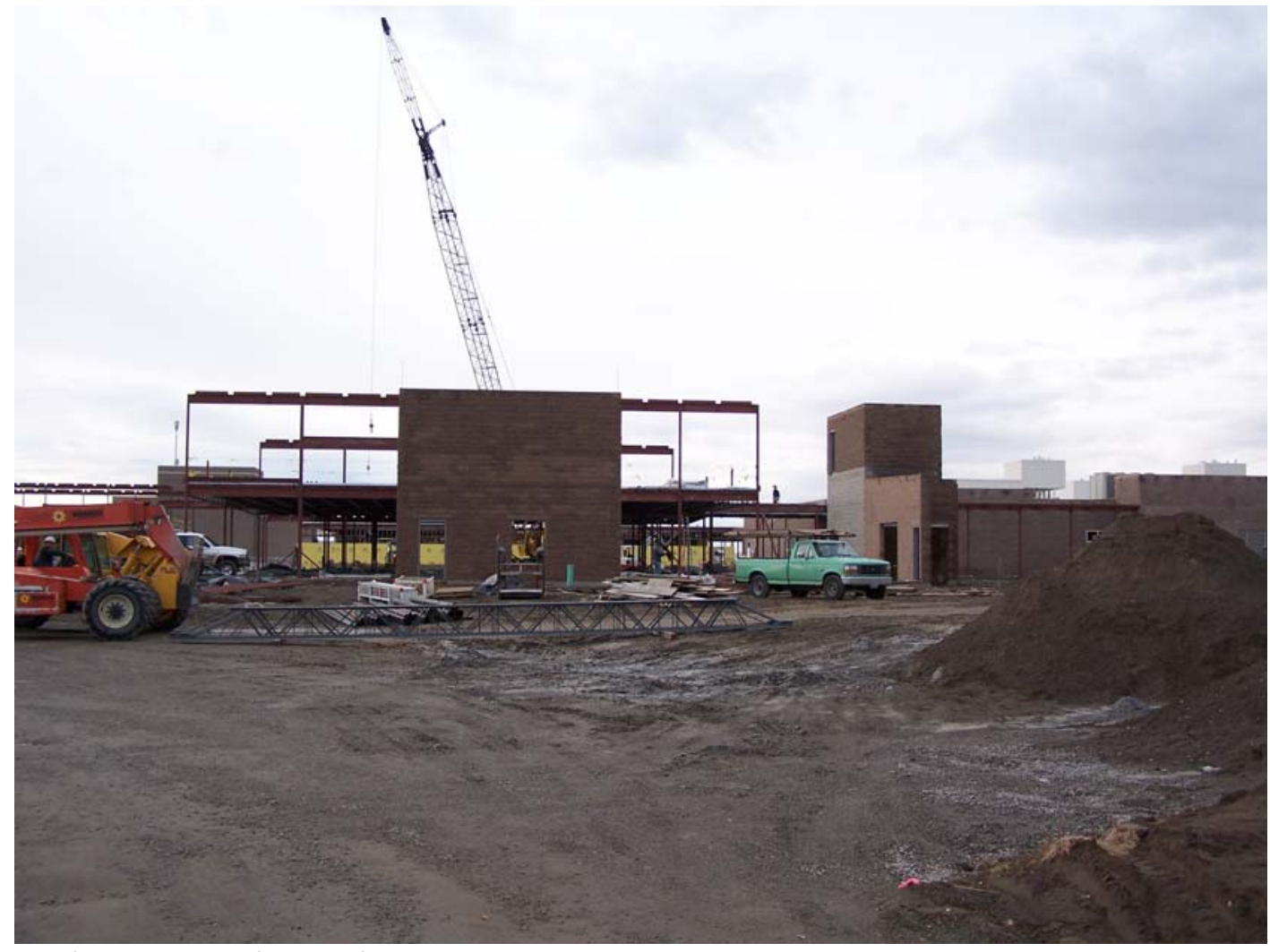

Under construction at the campus 